\title{
Upper extremity kinematics and muscle activation patterns in subjects with facioscapulohumeral dystrophy
}

Citation for published version (APA):

Bergsma, A., Murgia, A., Cup, E. H., Verstegen, P. P., Meijer, K., \& de Groot, I. J. (2014). Upper extremity kinematics and muscle activation patterns in subjects with facioscapulohumeral dystrophy. Archives of Physical Medicine and Rehabilitation, 95(9), 1731-1741. https://doi.org/10.1016/j.apmr.2014.03.033

Document status and date:

Published: 01/01/2014

DOI:

10.1016/j.apmr.2014.03.033

Document Version:

Publisher's PDF, also known as Version of record

\section{Document license:}

Taverne

Please check the document version of this publication:

- A submitted manuscript is the version of the article upon submission and before peer-review. There can be important differences between the submitted version and the official published version of record.

People interested in the research are advised to contact the author for the final version of the publication, or visit the DOI to the publisher's website.

- The final author version and the galley proof are versions of the publication after peer review.

- The final published version features the final layout of the paper including the volume, issue and page numbers.

Link to publication

\footnotetext{
General rights rights.

- You may freely distribute the URL identifying the publication in the public portal. please follow below link for the End User Agreement:

www.umlib.nl/taverne-license

Take down policy

If you believe that this document breaches copyright please contact us at:

repository@maastrichtuniversity.nl

providing details and we will investigate your claim.
}

Copyright and moral rights for the publications made accessible in the public portal are retained by the authors and/or other copyright owners and it is a condition of accessing publications that users recognise and abide by the legal requirements associated with these

- Users may download and print one copy of any publication from the public portal for the purpose of private study or research.

- You may not further distribute the material or use it for any profit-making activity or commercial gain

If the publication is distributed under the terms of Article $25 \mathrm{fa}$ of the Dutch Copyright Act, indicated by the "Taverne" license above, 


\title{
ORIGINAL ARTICLE
}

\section{Upper Extremity Kinematics and Muscle Activation Patterns in Subjects With Facioscapulohumeral Dystrophy}

\author{
Arjen Bergsma, MSc, ${ }^{a, b}$ Alessio Murgia, $\mathrm{PhD}^{\mathrm{c}}$ Edith $\mathrm{H}$. Cup, $\mathrm{PhD},{ }^{a}$ \\ Paul P. Verstegen, MSc, ${ }^{d}$ Kenneth Meijer, PhD, ${ }^{b}$ Imelda J. de Groot, MD, PhD ${ }^{a}$
}

From the ${ }^{a}$ Department of Rehabilitation, Donders Center for Neuroscience, Radboud University Medical Center, Nijmegen; ${ }^{b}$ Department of Human Movement Sciences, Faculty of Health, Medicine and Life Sciences, Maastricht University, Maastricht; ${ }^{c}$ Center for Human Movement Sciences, University Medical Center Groningen, University of Groningen, Groningen; and ${ }^{d}$ Focal Meditech BV, Tilburg, The Netherlands.

\begin{abstract}
Objective: To compare the kinematics and muscle activity of subjects with facioscapulohumeral dystrophy (FSHD) and healthy control subjects during the performance of standardized upper extremity tasks.

Design: Exploratory case-control study.

Setting: A movement laboratory.

Participants: Subjects $(\mathrm{N}=19)$ with FSHD $(n=11)$ and healthy control subjects $(n=8)$ were measured.

Interventions: Not applicable.

Main Outcome Measures: Kinematic data were recorded using a 3-dimensional motion capturing system. Muscle activities, recorded using electromyography, were obtained from 6 superficial muscles around the glenohumeral joint. Shoulder elevation and elbow flexion angles, and maximum electromyographic activity during the movements as a percentage of maximum voluntary contraction (MVC) were calculated.

Results: Kinematic differences between the FSHD group and the healthy control group were found in the shoulder elevation angle during single shoulder movements and both reaching tasks. In general, subjects with FSHD had higher percentages of muscle activation. The median activity of the trapezius was close to the MVC activity during the single shoulder movements. Moreover, deltoid and pectoralis muscles were also highly active.

Conclusions: Higher activation of the trapezius in subjects with FSHD indicates a mechanism that could help relieve impaired shoulder muscles during arm elevation around shoulder height. Compared with healthy subjects, persons with FSHD activated their shoulder muscles to a greater extent during movements that required arm elevation.
\end{abstract}

Archives of Physical Medicine and Rehabilitation 2014;95:1731-41

(C) 2014 by the American Congress of Rehabilitation Medicine

Muscular dystrophies, although varying in type and severity, are more or less progressive and disabling in time. ${ }^{1}$ Some forms of muscular dystrophy become symptomatic in infancy or childhood, whereas others do not become symptomatic until middle age or later. Facioscapulohumeral dystrophy (FSHD) is an autosomal dominant, slowly progressive type of muscular dystrophy. It is one

Supported by the national innovation program Pieken in de Delta (grant no. PID 102055). The funders played no role in study design, collection, analysis, interpretation of the data, writing the paper, or in the decision to submit the paper for publication. They accept no responsibility for the contents.

Disclosures: none. of the most common inherited muscular dystrophies, with an estimated prevalence 1 per 21,000 persons in the general population. ${ }^{2,3}$ In FSHD, the first signs of weakness are in the muscles of the face and shoulder girdle. ${ }^{4,5}$ Weakness of the shoulder girdle muscles results in impairment of arm function, including movements above the shoulder level ${ }^{5}$ and limitations in performing daily activities. ${ }^{6}$ When persons have weakened shoulder girdle muscles and move their arms to carry out daily tasks, contraction of the relatively spared shoulder girdle muscles results in protraction and medial rotation of the scapula. The inferior angle of the scapula tends to rotate medially, and the scapula separates from the ribcage. This so-called scapular winging is most apparent 
in upper extremity (UE) abduction but can also be found in UE forward flexion. ${ }^{7}$ When healthy subjects achieve a full range of shoulder motion, upward rotation and elevation of the scapula takes place. ${ }^{8,9}$ In contrast to healthy subjects, persons with FSHD cannot rotate the scapula laterally and are therefore unable to achieve a full range of shoulder motion. Furthermore, because of a decreased acromiohumeral space, there is an increased risk of impingement.

Persons with FSHD have an increased impingement risk because of the use of compensatory movements, such as ballistic movements, in order to lift the upper arm and overcome the lack of strength of the scapular-stabilizing muscles and ultimately to rotate the scapula. Innovative arm supports may help persons with FSHD perform arm activities that would cost considerable effort or possible damage. To develop such support systems, knowledge of UE kinematics and muscle activity in FSHD is needed.

Several studies have focused on quantifying UE movements with different techniques. Basic arm function in FSHD has often been quantified using the Brooke scale, ${ }^{10-14}$ which is an observational scale ranging from 1 to 6 (a higher score indicates more limitation in arm function). More specific knowledge concerning muscle activity is confined mainly to manual muscle testing (MMT) of muscle groups during performance of joint movements such as elbow flexion. ${ }^{6,10,12,13}$ Some studies present MMT scores of muscle groups instead of overall scores only. ${ }^{10}$ However, the strength of an individual muscle can hardly be measured, and using MMT provides very limited knowledge on the coordination between muscles. Coordination of UE muscles during reaching tasks has mostly been studied in healthy elderly persons ${ }^{15,16}$ and those who have had a stroke. ${ }^{17,18}$ Only 1 study ${ }^{14}$ to date has described UE kinematics and muscle activation in FSHD. In that study, the movement and muscle activity of the biceps brachii, triceps, and deltoid of a group of persons with FSHD were described during a simulated drinking task and were compared with a group of healthy controls. The pattern of muscle activity and movement in the FSHD group during the simulated drinking task involved more cocontraction of muscles and more abduction and flexion of the shoulder and elbow joints compared with the movement pattern of healthy controls. ${ }^{14}$ Electromyographic activity as a percentage of the maximum voluntary contraction (\%MVC) was also higher in the FSHD group compared with healthy controls. Bakhtiary et $\mathrm{al}^{14}$ also hypothesized that individuals with FSHD have fewer intact muscle fibers and will therefore recruit a higher percentage of the remaining muscle fibers to perform tasks. Bakhtiary's study ${ }^{14}$ provided the first knowledge of the arm function in FSHD during 1 daily task. However, muscles that are responsible for stabilizing the scapula were not investigated.

The aim of the current study was to gain a deeper understanding of shoulder and elbow movements in FSHD. The purpose was to investigate the kinematics of the UE and the involvement of specific proximal muscles during singular joint movements, reaching tasks, and gross motor tasks in persons with FSHD and healthy controls.

\footnotetext{
List of abbreviations:

FSHD facioscapulohumeral dystrophy

MMT manual muscle testing

\%MVC percentage of maximum voluntary contraction

MVC maximum voluntary contraction

SAA shoulder abduction-adduction

SFE shoulder flexion-extension

UE upper extremity
}

\section{Methods}

\section{Participants}

Eleven persons with FSHD (4 men, 7 women; mean age \pm SD, $33.9 \pm 11.5 \mathrm{y} ; 10$ right dominant, 1 left dominant) and 8 healthy volunteers (5 men, 3 women; mean age $\pm \mathrm{SD}, 49.9 \pm 9.8 \mathrm{y}$; all right dominant) participated in the study. The dominant side was tested in all persons. All persons gave written informed consent. None of the healthy participants had a history of musculoskeletal or neurologic problems. Persons with FSHD were recruited by an invitation letter from the Dutch patient organization of persons with muscle diseases (Spierziekten Nederland). All persons with FSHD scored 2 to 3 on the Brooke scale, ${ }^{19}$ which meant they were able to raise a $250-\mathrm{mL}$ glass of water to the mouth. Subjects were excluded if they had sustained previous upper limb trauma (eg, bone fractures or surgery). Ethical approval was obtained for the study (Ethical Committee Arnhem-Nijmegen, NL39024.091.11), and the study was conducted in accordance with guidelines of the Helsinki protocol.

\section{Data recording}

All assessments were performed using a standardized protocol at a motion analysis laboratory (Maastricht University, The Netherlands). The movements were recorded with an 8 Vicon MX camera system ${ }^{\text {a }}$ operating at a frequency of $200 \mathrm{~Hz}$, and the data were filtered using spline interpolation (Woltring). Reflective markers were attached on the subject's body following the guidelines of the upper limb model ${ }^{20}$ (fig 1). Because the scapula rotates underneath the skin, it is difficult to detect rotation and tilting of the scapula with this method.

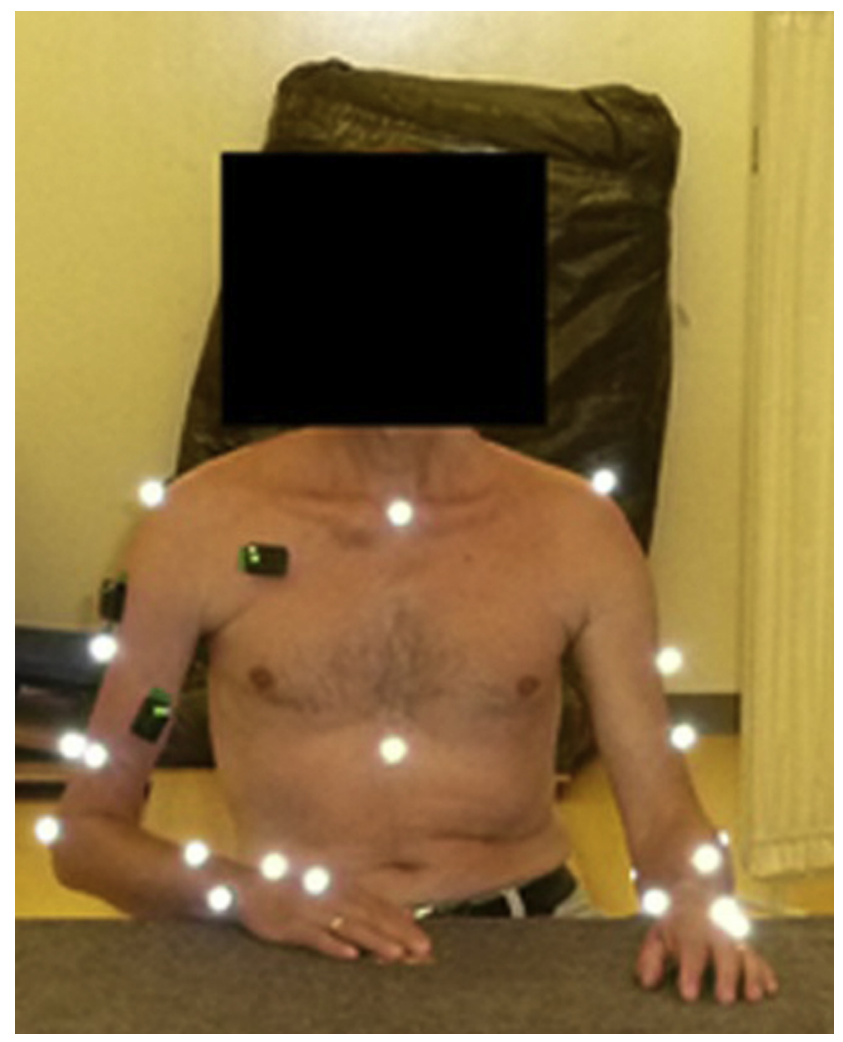

Fig 1 Marker setup for unassisted movements. 
The movement protocol consisted of 2 single-joint movements (shoulder abduction-adduction [SAA] and shoulder flexionextension [SFE]), 2 forward-reaching tasks at shoulder level (to the ipsilateral side and contralateral side), and 2 gross motor tasks (hand to mouth and pulling/pushing of an object on a table). Electromyographic data from the biceps brachii, deltoid (lateral part), triceps brachii, trapezius (upper part), pectoralis major (clavicular part), and latissimus dorsi (important during UE adduction $^{21}$ ) muscles were collected with Delsys Trigno sensors ${ }^{\mathrm{b}}$ operating at $2 \mathrm{kHz}$. The serratus anterior is also important for coordinated UE movements and scapula stabilization. However, since the serratus muscle is composed of several bellies, it cannot be measured reliably using this method of bipolar surface electrodes and was left out of this protocol. Sensors were attached following the guidelines by the SENIAM group ${ }^{22}$ and Delagi et $\mathrm{al}^{23}$ The skin was prepared by shaving the skin surface if needed and cleaning the skin with alcohol. Each task consisted of 3 repetitions of the same movement with a common start and endpoint, and at self-selected speed. Each of the healthy participants was asked to sit on a height-adjustable chair without a backrest. During the reaching and the gross motor tasks, a table was also placed in front of the subject. When the table was used, the height of the chair was adjusted until the elbow angle was $90^{\circ}$ with the hand resting on the table and the upper arm in a vertical position (see fig 1). The target for the reaching tasks was placed at arm length and 1 shoulder width on the ipsilateral or contralateral side at shoulder level. In the SAA and SFE tasks, subjects were instructed to complete the task up to their maximum voluntary active range of motion. The starting point for the hand in the reaching tasks and the hand to the mouth movement was on the table at the subject's midline and about $20 \mathrm{~cm}$ from the abdomen. Table 1 summarizes the tasks.

Before execution of the set of movements, participants were asked to perform MVCs to record the maximum electromyographic activity for each of the 6 muscles. The electromyographic activities of the muscles were recorded during 3 seconds of isometric MVC, and each test was performed twice for each muscle. During execution of the MVCs, the subject was encouraged verbally to produce the maximal contraction. The positions in which the MVC were performed are summarized in table 2.

\section{Data processing}

\section{Analysis of kinematic parameters}

The joint angles were calculated using the Vicon upper limb model. For each person and each task, the mean of the maximum upper arm elevation and minimum and maximum elbow flexion angle of the 3 repetitions was calculated. Upper arm elevation was used because the clinical terms "flexion" and "abduction" can be confusing. Flexion followed by abduction would give different results than abduction followed by flexion. ${ }^{24}$ Flexion is elevation parallel to the sagittal plane, and abduction is elevation in the frontal plane. For both the control group and the FSHD group, the median values of maximum upper arm elevation and minimum and maximum elbow flexion angle were also calculated. The

Table 1 Tasks that were executed by the participants

\begin{tabular}{|c|c|c|c|}
\hline Movement & Instructions & Start Position & End Position \\
\hline \multicolumn{4}{|l|}{ Single joint movements } \\
\hline $\begin{array}{l}\text { Shoulder abduction- } \\
\text { adduction }\end{array}$ & $\begin{array}{l}\text { Move the arm sideward/upward as far as possible and move the arm back to } \\
\text { the start position. Keep the arms straight and the hand palm facing } \\
\text { forward. }\end{array}$ & & \\
\hline $\begin{array}{l}\text { Shoulder flexion- } \\
\text { extension }\end{array}$ & $\begin{array}{l}\text { Move the arm forward/upward as far as possible, then bring the arm back to } \\
\text { the start position. Keep the arm straight, with the hand palm facing } \\
\text { inward. }\end{array}$ & & \\
\hline \multicolumn{4}{|l|}{ Reaching tasks } \\
\hline $\begin{array}{l}\text { Reach up ipsilateral } \\
\text { - Active protraction scapula }\end{array}$ & Reach toward the target at shoulder height on the ipsilateral side. & & \\
\hline $\begin{array}{l}\text { Reach up contralateral } \\
\text { - Active protraction scapula }\end{array}$ & $\begin{array}{l}\text { Reach toward the target at shoulder height and } 1 \text { shoulder width on the } \\
\text { contralateral side. }\end{array}$ & & \\
\hline \multicolumn{4}{|l|}{ Gross motor tasks } \\
\hline $\begin{array}{l}\text { Bring the hand to the } \\
\text { mouth } \\
\text { - Active flexion } \\
\text { - Active supination } \\
\text { - Passive pronation }\end{array}$ & $\begin{array}{l}\text { Bring the fingers of the hand to the mouth and back to the start position on } \\
\text { the table top. Wrist about } 20 \mathrm{~cm} \text { in front of abdomen. }\end{array}$ & & \\
\hline Pushing-pulling & $\begin{array}{l}\text { Push the object as far as possible forward from the starting position without } \\
\text { moving the chest and then pull it back. Use the lateral edge of the object } \\
\text { as reference to follow a line on the table put at } 1 \text { shoulder width from the } \\
\text { middle. }\end{array}$ & & \\
\hline
\end{tabular}

NOTE. Not all participants were wheelchair bound; the figures are intended only for illustrative purposes. 
Table 2 MVC starting positions and instructions

\begin{tabular}{|c|c|c|}
\hline Muscle & Start Position & Instruction \\
\hline Biceps brachii & $\begin{array}{l}90^{\circ} \text { elbow flexion, palm facing upward. Examiner takes the hand and } \\
\text { provides resistance to resist elbow joint flexion. }\end{array}$ & $\begin{array}{l}\text { Flex the elbow as hard as possible, against } \\
\text { the examiner's hand. }\end{array}$ \\
\hline Deltoid (lateral part) & $\begin{array}{l}45^{\circ} \text { of shoulder abduction and extended elbow. The examiner holds } \\
\text { the arm and resists abduction of the shoulder. }\end{array}$ & $\begin{array}{l}\text { Abduct the arm against the force } \\
\text { generated by the examiner's hand. }\end{array}$ \\
\hline Triceps brachii & $\begin{array}{l}90^{\circ} \text { elbow flexion and } 90^{\circ} \text { abduction. The examiner supports the elbow } \\
\text { and holds the wrist, to resist elbow joint extension. }\end{array}$ & $\begin{array}{l}\text { Extend the elbow against the examiner's } \\
\text { hand. }\end{array}$ \\
\hline Trapezius (upper part) & $\begin{array}{l}\text { Arms hanging vertically beside the trunk. The examiner's hands are } \\
\text { placed on top of the shoulders, to prevent upper arm elevation. }\end{array}$ & $\begin{array}{l}\text { Elevate both shoulders, against the } \\
\text { examiner's hands. }\end{array}$ \\
\hline $\begin{array}{l}\text { Pectoralis major } \\
\text { (clavicular part) }\end{array}$ & $\begin{array}{l}\text { Upper arm abducted } 90^{\circ} \text { and the elbow flexed in } 90^{\circ} \text {. One hand of the } \\
\text { examiner supports the forearm, while the other hand is used to } \\
\text { resist adduction and flexion of the shoulder in the horizontal plane. }\end{array}$ & $\begin{array}{l}\text { Flex the upper arm against the hand of } \\
\text { the examiner at the upper arm. }\end{array}$ \\
\hline Latissimus dorsi & $\begin{array}{l}90^{\circ} \text { shoulder abduction, } 90^{\circ} \text { elbow flexion, and external rotation of } \\
\text { the upper arm. One hand of the examiner supports the elbow to } \\
\text { resist adduction of the shoulder, while the other hand is used to } \\
\text { keep the wrist in position. }\end{array}$ & Adduct the upper arm. \\
\hline
\end{tabular}

upper arm elevation and elbow flexion angles were selected because they are most influenced by the effects of gravity and would thus require a greater muscle activity to compensate for the weight of the arm. To avoid a confounding effect resulting from the starting and finishing of the movement, the second repetition of each task was used for further analysis. The movement of the hand marker was considered as the starting point. The duration of each movement was compared between the control group and the FSHD group.

\section{Electromyographic activity}

The recorded electromyographic data were filtered with a fourthorder Butterworth bandpass filter from 20 to $450 \mathrm{~Hz}$ and then rectified. For each person and each muscle, an MVC norm value was calculated. This was defined as the maximum value of the rectified signal of both MVC contractions. The \% MVC of the activities was then expressed as the electromyographic signal divided by the MVC norm for the corresponding muscle. For each movement, muscle, and person, the mean of the maximal \%MVC of the 3 repetitions was then calculated. Moreover, the muscle activation patterns were analyzed by comparing the onset times of the individual muscle contractions. For each task, the onset time of a muscle was calculated for the second repetition. The onset time was defined as the percentage of the duration of the movement where the electromyographic activity was higher than $20 \%$ of the maximum electromyographic value for a period of at least 0.2 seconds during that specific movement (fig 2).

\section{Statistics}

The data were not normally distributed, so the median and interquartile ranges were used to describe the data. The nonparametric Wilcoxon rank-sum test was used to compare the medians between the FSHD group and the healthy control group for each task; the effect size was also calculated. The significance level was set at $\alpha=.05$.

\section{Results}

Only 1 person with FSHD was able to elevate the arm above $120^{\circ}$ during the 2 single joint movements of SAA and SFE. All persons were able to complete the reaching tasks and the gross motor tasks. Three tasks (SAA, reach up ipsilateral, reach up contralateral) were performed significantly slower (completion time approximately $25 \%-40 \%$ slower) by the FSHD group than by the healthy control group. Table 3 gives the kinematic and electromyographic parameters recorded during execution of different tasks, from the FSHD and the control group.

\section{Arm kinematics}

The data depicted in figure 3 represent the upper arm elevation angles of the healthy control group and the FSHD group. Significant differences between the FSHD group and the healthy control group were found in the upper arm elevation angle during SAA and SFE movements and during the 2 reaching tasks (see table 3). A larger variance was found in the maximum upper arm elevation angle of the SAA and SFE movements in the FSHD group. In addition, the FSHD group showed less extension of the elbow during the contralateral reaching task (fig 4, see table 3). Significant differences were found in the duration of the shoulder abduction movement, the ipsilateral reaching task, and the hand to the mouth task $(P=.02, P=.04$, and $P=.01$, respectively).

\section{Muscle activation}

On average, the maximum electromyographic activation as \%MVC was significantly higher in the FSHD group than in the control group (table 4, fig 5). During the SAA movement, the trapezius activity in the FSHD group was significantly higher than that of the control group (respectively, $115 \%$ and 35\%). In addition, during the 2 reaching tasks, the maximum trapezius activity was also significantly higher in the FSHD group (median 59\% and $47 \%$ of MVC in the FSHD group vs $10 \%$ and $13 \%$ in the control group). Compared with the healthy control group, in the FSHD group the maximum biceps brachii activity was significantly higher during the SFE movement and both reaching tasks, which included upper arm elevation and flexion. Moreover, the maximum activity of the biceps during these movements was higher than during the hand to the mouth task. During the SFE movement and the reaching tasks, the maximum triceps activity was also significantly higher in the FSHD group. The maximum activity of the deltoid muscle was only significantly higher in the FSHD group compared with the control group during the 
Onset muscle activity

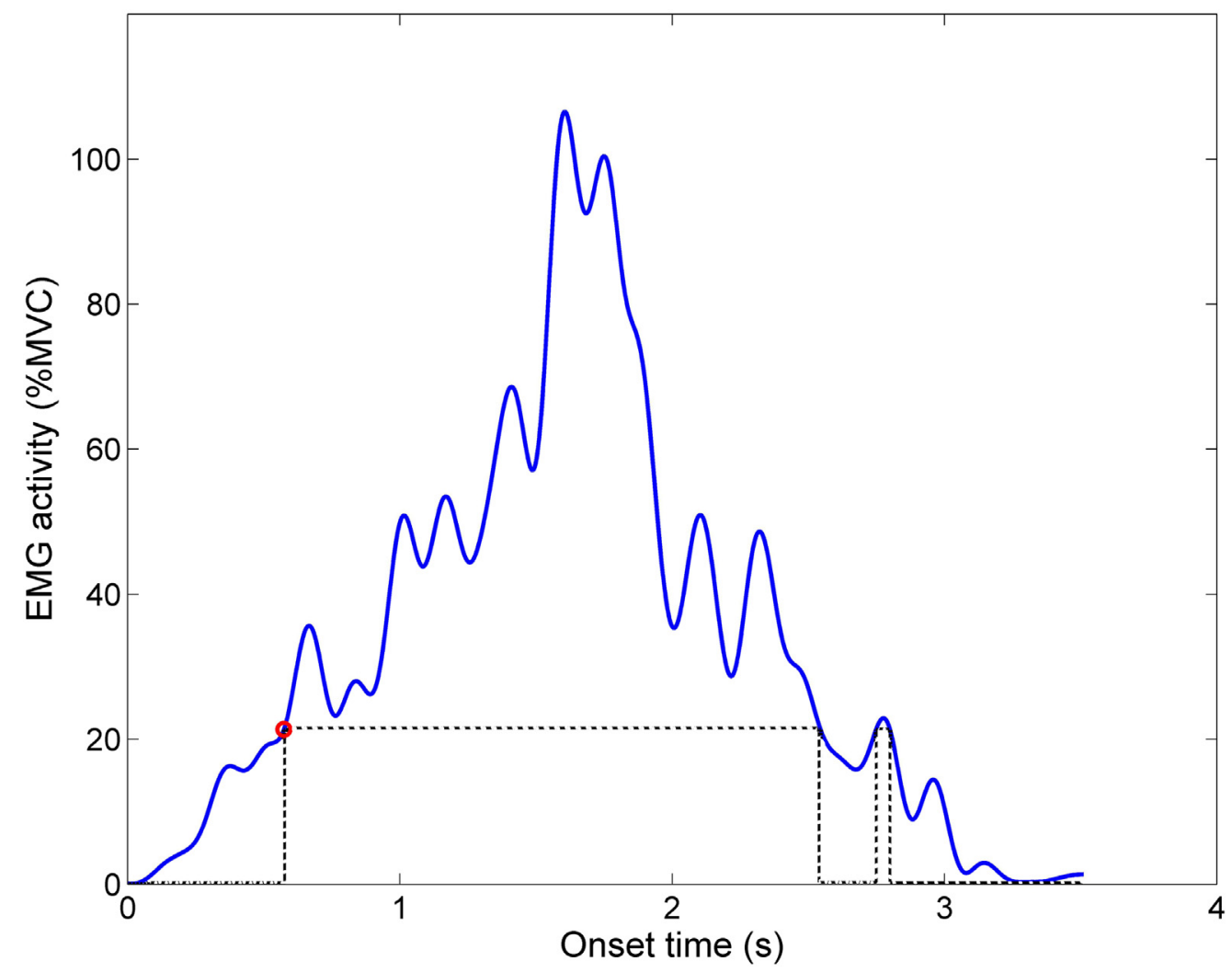

Fig 2 Onset time of the muscle activity. The continuous line represents an EMG signal, and the dashed line indicates when the muscle activity was more than $20 \%$ of the maximum EMG value for a period of at least 0.2 seconds. The circle represents the point that is considered as onset time of the muscle activity. Abbreviation: EMG, electromyographic.

ipsilateral reaching task and the hand to the mouth task. The maximum activity of the pectoralis was significantly higher in the FSHD group during all tasks. The maximum activity of the latissimus muscle was only significantly higher in the FSHD group during the hand to the mouth task. Visual inspection of the timing of muscle activation did not reveal any difference between the control group and the FSHD group.

\section{Discussion}

The aim of this study was to gain a deeper understanding of shoulder and elbow movements and the shoulder muscle activation during single joint movements, reaching tasks, and gross motor tasks in persons with FSHD. The main differences in the kinematics were found in the upper arm elevation angles, which were smaller in the FSHD group during shoulder abduction and flexion movements and the 2 reaching tasks. Only 2 subjects with FSHD were able to lift their arm to about $90^{\circ}$ during shoulder abduction and flexion. This is in line with the clinical picture of persons with FSHD. Persons with FSHD also had much higher muscle activity during task performance in all 6 muscles that were investigated. The highest activity as \%MVC was present in the trapezius.

To understand the findings, it is useful to differentiate between 2 phases occurring during shoulder abduction, shoulder flexion, or both. A first phase includes arm elevation between 0 and $90^{\circ}$; in a second phase, this occurs from $90^{\circ}$ and beyond. During the first phase, the deltoid muscle initiates upper arm elevation together with other scapulohumeral muscles. ${ }^{25}$ The maximal deltoid activity was shown to be lower in the FSHD group than in the control group for the SAA and SFE tasks. However, this result could have been induced by the greater arm elevation achieved by the healthy controls, although a possible sparing of the deltoid muscle to avoid undesired movements of the scapula could not be ruled out and should be further investigated. When axioscapular muscles such as the serratus anterior and trapezius cannot stabilize the scapula, contraction of the deltoid muscle may not only elevate the humerus but can also result in undesired movement of the scapula. $^{25,26}$

In this study it was hypothesized that the trapezius would be highly active in FSHD in an attempt to rotate and elevate the scapula. In a healthy situation, the upper trapezius together with the lower trapezius and serratus anterior are responsible for stabilizing the scapula to the thoracic cage. The serratus anterior counterbalances the external moment around the sternoclavicular and acromioclavicular joints induced by the weight of the arm during UE abduction and flexion. ${ }^{21}$ In addition, one of the most important functions of the trapezius occurs during the second phase of arm elevation from $90^{\circ}$ and beyond when the trapezius is involved in rotating the scapula together with the serratus anterior. $^{21,25,27}$ Serratus anterior activity was not recorded in this study. Inappropriate functioning of the serratus anterior muscle has, however, been mentioned as a cause for scapular winging, ${ }^{26,28,29}$ a clinical symptom that is present in FSHD. ${ }^{26,30}$ Winging of the scapula results in lower acromion elevation, thus leading to a lower maximal elevation angle of the humerus. ${ }^{8}$ The 
Table 3 Maximum angles during execution of tasks

\begin{tabular}{|c|c|c|c|c|c|c|c|c|}
\hline \multirow[b]{2}{*}{ Task } & \multicolumn{2}{|c|}{ Max Upper Arm Elevation (deg) } & \multicolumn{2}{|c|}{ Max Elbow Flexion (deg) } & \multicolumn{2}{|c|}{ Min Elbow Flexion (deg) } & \multicolumn{2}{|l|}{ Duration (s) } \\
\hline & Median & IQR & Median & IQR & Median & IQR & Median & IQR \\
\hline \multicolumn{9}{|l|}{$\overline{\text { SAA }}$} \\
\hline Control & 144.9 & $141.0-145.9$ & 38.7 & $35.3-44.4$ & 22.6 & $21.4-27.9$ & 3.8 & $3.2-5.3$ \\
\hline FSHD & $65.8\left(P<.01^{*} ; r=-.83\right)$ & $60.5-81.3$ & $41.2(P=.49 ; r=-.17)$ & $33.5-56.9$ & $21.5(P=.60 ; r=-.13)$ & $19.9-33.5$ & $5.6\left(P=.02^{*} ; r=-.54\right)$ & $5.1-7.3$ \\
\hline \multicolumn{9}{|l|}{ SFE } \\
\hline Control & 147.6 & $144.8-149.7$ & 45.6 & $35.2-54.3$ & 15.8 & $13.5-23.4$ & 3.7 & $3.0-4.3$ \\
\hline FSHD & $81.6\left(P<.01^{*} ; r=-.83\right)$ & $67.6-96.3$ & $40.1(P=.54 ; r=-.15)$ & $27.6-53.3$ & $16.4(P=1.00 ; r=.00)$ & $13.5-22.2$ & $4.7(P=.13 ; r=-.36)$ & $3.0-6.4$ \\
\hline \multicolumn{9}{|c|}{ 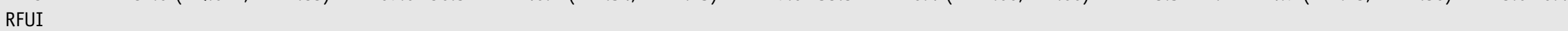 } \\
\hline Control & 83.8 & $78.0-90.6$ & 98.5 & $93.2-100.9$ & 20.6 & $17.3-30.7$ & 2.4 & $2.1-2.7$ \\
\hline FSHD & $68.7\left(P<.01^{*} ; r=-.74\right)$ & $66.2-77.1$ & $94.0(P=.35 ; r=-.23)$ & $91.6-99.0$ & $24.8(P=.24 ; r=-.28)$ & $16.6-34.8$ & $3.2\left(P<.00^{*} ; r=-.63\right)$ & $2.9-4.1$ \\
\hline \multicolumn{9}{|l|}{ RFUC } \\
\hline Control & 85.6 & $84.3-93.9$ & 95.7 & $92.8-105.9$ & 18.6 & $13.4-23.7$ & 2.4 & $2.2-2.8$ \\
\hline FSHD & $69.1\left(P<.01^{*} ; r=-.64\right)$ & $67.1-83.2$ & $96.3(P=.97 ; r=-.02)$ & $91.9-105.5$ & $26.9\left(P=.01^{*} ; r=-.59\right)$ & $21.1-38.2$ & $3.2(P=.05 ; r=-.46)$ & $2.5-3.7$ \\
\hline \multicolumn{9}{|c|}{ 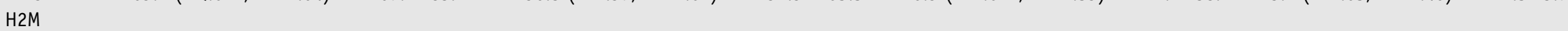 } \\
\hline Control & 49.5 & $42.9-53.1$ & 136.1 & $131.3-139.6$ & 82.2 & $78.2-87.8$ & 2.2 & $1.9-2.6$ \\
\hline FSHD & $46.2(P=1.00 ; r=.00)$ & $42.4-59.7$ & $134.5(P=.51 ; r=-.16)$ & $129.0-138.3$ & $87.5(P=.17 ; r=-.33)$ & $82.9-94.2$ & $3.8\left(P=.04^{*} ; r=-.47\right)$ & $2.3-4.0$ \\
\hline \multicolumn{9}{|l|}{ PP } \\
\hline Control & 69.5 & $63.6-74.4$ & 94.4 & $92.1-104.4$ & 17.1 & $14.3-20.2$ & 3.9 & $3.1-4.2$ \\
\hline FSHD & $64.7(P=.15 ; r=-.34)$ & $58.7-68.8$ & $100.3(P=.21 ; r=-.30)$ & $97.0-105.9$ & $13.2(P=.21 ; r=-.30)$ & $10.6-23.9$ & $4.7(P=.08 ; r=-.42)$ & $3.4-5.7$ \\
\hline
\end{tabular}



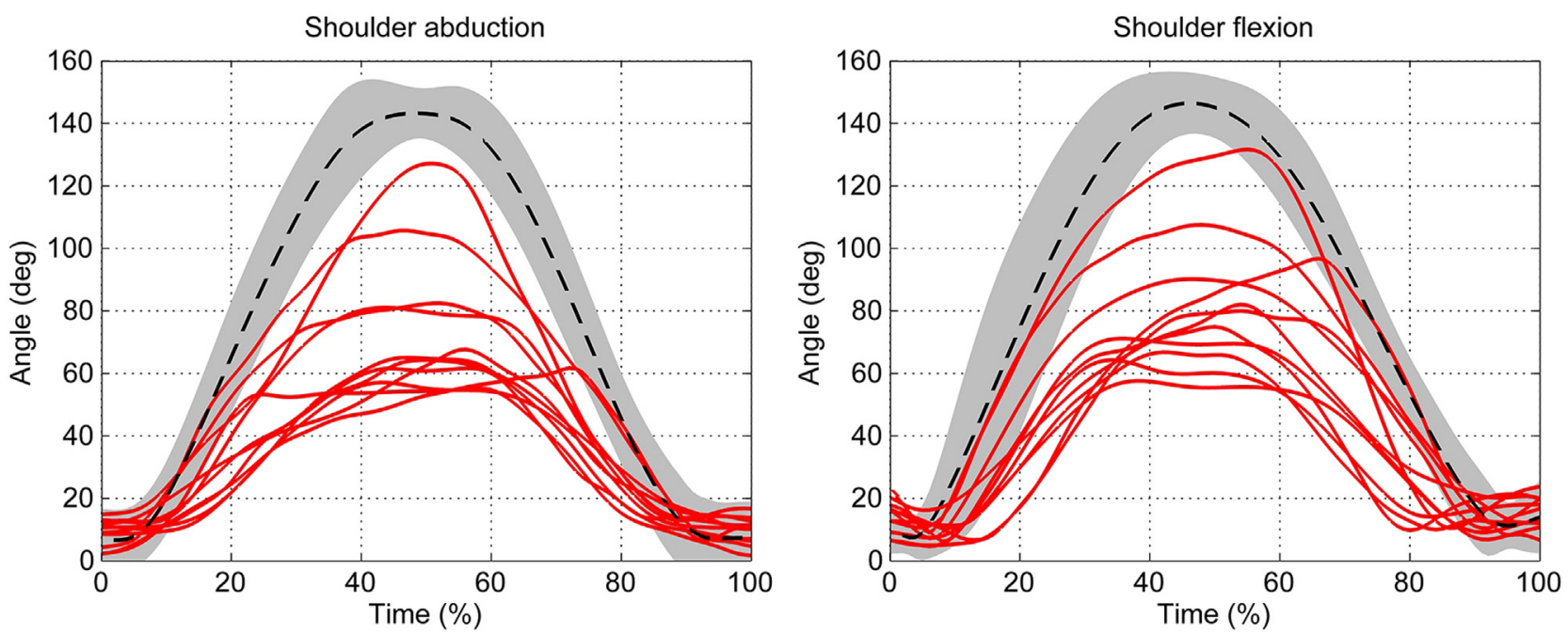

Fig 3 The data representing the maximum upper arm elevation angle of shoulder abduction (left) and flexion (right). The gray band represents the $95 \%$ confidence interval of the control group, the dashed lines represent the average of the control group, and the red lines represent the persons with FSHD.

maximum \%MVC activity of the trapezius was higher in subjects with FSHD compared with healthy subjects, and was even close to or higher than its activity during MVC during tasks where maximal UE elevation was required. This may indicate that the trapezius contributed to humeral elevation by rotating and elevating the scapula.

In the control group, the median biceps activity during movements that required upper arm elevation was lower than during the hand to the mouth task. In the FSHD group, the opposite was observed, indicating that the biceps brachii muscle supports upper arm elevation in FSHD. This is consistent with the biomechanical function of this muscle that, according to Itoi et al, ${ }^{31}$ can also function as an anterior stabilizer of the glenohumeral joint and thus assist in forward flexion of the shoulder joint. ${ }^{31}$ Bakhtiary, ${ }^{14}$ who studied the kinematics and electromyography in FSHD during a simulated drinking task, found similar results. They concluded that the muscles around the shoulder and rotator cuff are weaker in FSHD, and that the biceps is therefore recruited as an arm flexor. In the present study, more tasks were investigated. The complex interaction between superficial shoulder muscles was evident in muscle activation patterns that showed more cocontraction in the muscle activity in FSHD compared with healthy controls. During the reaching tasks, more cocontraction was present in the deltoid, trapezius, pectoralis, and biceps brachii muscles. No difference in the starting time was found.

\section{Study limitations}

Few methodological aspects can be considered as limitations of this study. The MVC was performed manually, while resistance was provided by 1 of the researchers. In some cases, it was difficult to immobilize the joints properly by hand. The maximum $\% \mathrm{MVC}$ activity of the upper trapezius muscle during shoulder abduction and flexion was close to or higher than the electromyographic activity measured during MVC. It is known that reduced concentration, motivation and fear to contract the muscles or restrictions in the range of motion can influence a person's voluntary effort during MVC. ${ }^{32,33}$ It is possible that these factors
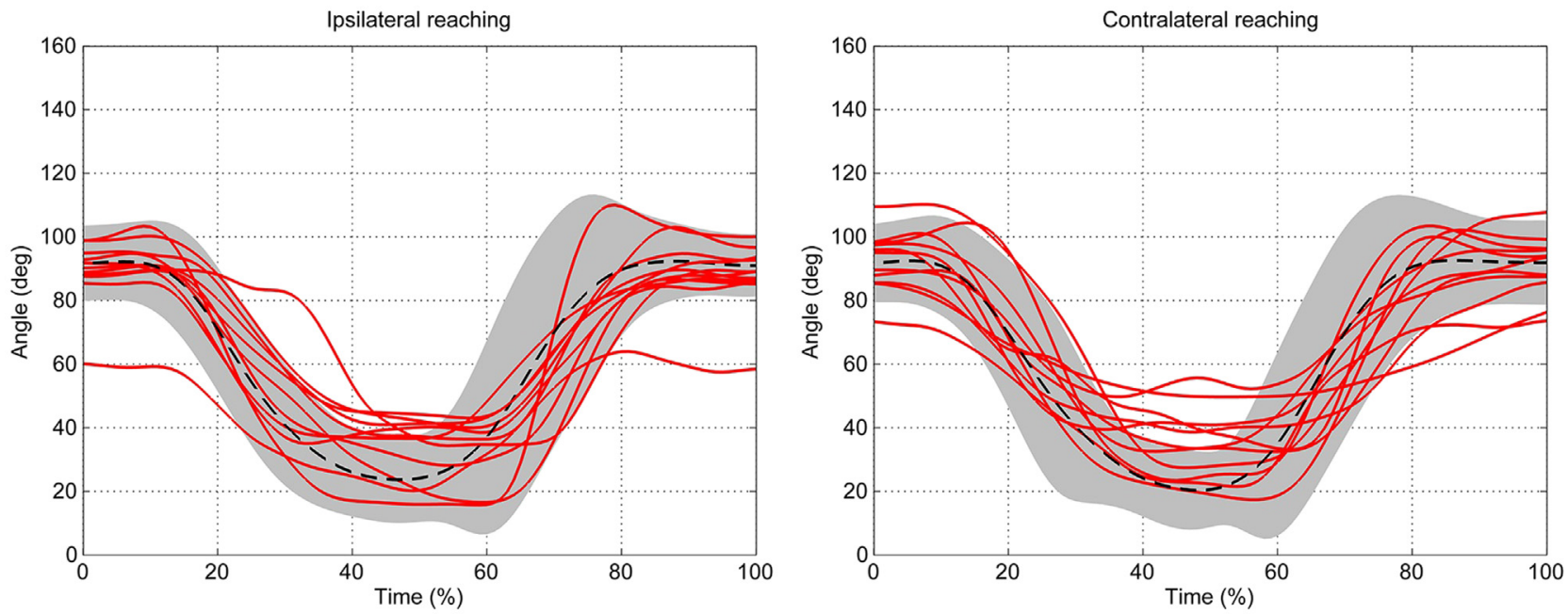

Fig 4 Elbow flexion angles during reaching tasks. The gray band represents the $95 \%$ confidence interval of the control group, the dashed lines represent the average of the control group, and the red lines represent the persons with FSHD. 
Table 4 Maximum electromyographic activation during execution of tasks

\begin{tabular}{|c|c|c|c|c|c|c|c|c|c|c|c|c|}
\hline \multirow[b]{3}{*}{ Task } & \multicolumn{12}{|c|}{ Max EMG } \\
\hline & \multicolumn{2}{|c|}{$\begin{array}{c}\text { Biceps } \\
(\% M V C)\end{array}$} & \multicolumn{2}{|c|}{$\begin{array}{l}\text { Deltoid } \\
(\% M V C) \\
\end{array}$} & \multicolumn{2}{|c|}{$\begin{array}{l}\text { Triceps } \\
(\% M V C)\end{array}$} & \multicolumn{2}{|c|}{$\begin{array}{c}\text { Trapezius } \\
(\% M V C)\end{array}$} & \multicolumn{2}{|c|}{$\begin{array}{c}\text { Pectoralis } \\
(\% M V C)\end{array}$} & \multicolumn{2}{|c|}{$\begin{array}{c}\text { Latissimus } \\
(\% M V C)\end{array}$} \\
\hline & Median & IQR & Median & IQR & Median & IQR & Median & IQR & Median & IQR & Median & IQR \\
\hline \multicolumn{13}{|l|}{ SAA } \\
\hline Control & 3 & $3-11$ & 60 & $45-144$ & 11 & $5-16$ & 35 & $18-68$ & 5 & $3-9$ & 21 & $15-26$ \\
\hline FSHD & $\begin{array}{c}16(P=.05 \\
\quad r=-.46)\end{array}$ & $8-22$ & $\begin{array}{c}85(P=.72 \\
\quad r=-.10)\end{array}$ & $59-95$ & $\begin{array}{c}20(P=.09 \\
\quad r=-.40)\end{array}$ & $8-38$ & $\begin{array}{c}115\left(P<.01^{*}\right. \\
\quad r=-.64)\end{array}$ & $68-149$ & $\begin{array}{c}28\left(P=.01^{*}\right. \\
r=-.57)\end{array}$ & $8-40$ & $\begin{array}{r}16(P=.66 \\
r=-.11)\end{array}$ & $9-59$ \\
\hline \multicolumn{13}{|l|}{ SFE } \\
\hline Control & 5 & $3-16$ & 69 & $55-122$ & 8 & $3-11$ & 40 & $25-57$ & 16 & $7-20$ & 23 & $18-29$ \\
\hline FSHD & $\begin{array}{c}27\left(P=.02^{*}\right. \\
r=-.55)\end{array}$ & $13-46$ & $\begin{array}{r}56(P=.27 \\
\quad r=-.27)\end{array}$ & $45-83$ & $\begin{array}{c}17\left(P=.01^{*}\right. \\
\quad r=-.57)\end{array}$ & $10-36$ & $\begin{array}{c}95(P=.06 \\
\quad r=-.44)\end{array}$ & $30-182$ & $\begin{array}{c}69\left(P<.01^{*} ;\right. \\
r=-.83)\end{array}$ & $61-98$ & $\begin{array}{r}23(P=.84 ; \\
r=-.06)\end{array}$ & $7-92$ \\
\hline \multicolumn{13}{|l|}{ RFUI } \\
\hline Control & 4 & $3-7$ & 18 & $13-23$ & 3 & $2-4$ & 10 & $9-15$ & 3 & $2-8$ & 7 & $4-16$ \\
\hline FSHD & $\begin{array}{c}14\left(P<.01^{*} ;\right. \\
r=-.63)\end{array}$ & $7-32$ & $\begin{array}{c}52\left(P<.01^{*}\right. \\
r=-.68)\end{array}$ & $40-64$ & $\begin{array}{c}10\left(P<.01^{*}\right. \\
r=-.70)\end{array}$ & $6-16$ & $\begin{array}{c}59\left(P<.01^{*}\right. \\
\quad r=-.66)\end{array}$ & $21-141$ & $\begin{array}{c}29\left(P<.01^{*} ;\right. \\
r=-.74)\end{array}$ & $13-54$ & $\begin{array}{c}18(P=.11 \\
\quad r=-38)\end{array}$ & $8-32$ \\
\hline \multicolumn{13}{|l|}{ RFUC } \\
\hline Control & 4 & $2-8$ & 22 & $17-27$ & 4 & $1-5$ & 13 & $11-22$ & 20 & $14-24$ & 20 & $12-33$ \\
\hline FSHD & $\begin{array}{c}14\left(P<.01^{*} ;\right. \\
r=-.63)\end{array}$ & $7-34$ & $\begin{array}{r}51(P=.05 \\
\quad r=-.46)\end{array}$ & $21-65$ & $\begin{array}{c}11\left(P<.01^{*}\right. \\
r=-.72)\end{array}$ & $7-16$ & $\begin{array}{c}47\left(P=.01^{*}\right. \\
r=-.59)\end{array}$ & $20-101$ & $\begin{array}{c}81\left(P<.01^{*}\right. \\
r=-.78)\end{array}$ & $45-92$ & $\begin{array}{r}26(P=.66 \\
r=-.11)\end{array}$ & $18-57$ \\
\hline \multicolumn{13}{|l|}{$\mathrm{H} 2 \mathrm{M}$} \\
\hline Control & 6 & $4-7$ & 3 & $2-3$ & 1 & $0-1$ & 6 & $3-12$ & 8 & $4-11$ & 3 & $2-4$ \\
\hline FSHD & $\begin{array}{c}6(P=.15 \\
\quad r=-.35)\end{array}$ & $5-51$ & $\begin{array}{c}6\left(P<.01^{*}\right. \\
\quad r=-.65)\end{array}$ & $4-12$ & $\begin{array}{c}2\left(P=.02^{*}\right. \\
\quad r=-.53)\end{array}$ & $1-7$ & $\begin{array}{c}7(P=.24 \\
\quad r=-.29)\end{array}$ & $6-20$ & $\begin{array}{c}23\left(P<.01^{*}\right. \\
r=-.67)\end{array}$ & $14-101$ & $\begin{array}{c}7\left(P=.02^{*} ;\right. \\
\quad r=-.53)\end{array}$ & $3-22$ \\
\hline \multicolumn{13}{|l|}{ PP } \\
\hline Control & 1 & $1-4$ & 17 & $11-19$ & 6 & $3-9$ & 8 & $6-13$ & 4 & $2-11$ & 6 & $5-16$ \\
\hline FSHD & $\begin{array}{c}5\left(P=.01^{*}\right. \\
\quad r=-.61)\end{array}$ & $2-17$ & $\begin{array}{r}23(P=.24 \\
\quad r=-.28)\end{array}$ & $15-25$ & $\begin{array}{r}23(P=.05 \\
\quad r=-.46)\end{array}$ & $6-55$ & $\begin{array}{r}32(P=.05 \\
\quad r=-.46)\end{array}$ & $11-43$ & $\begin{array}{c}16\left(P<.01^{*} ;\right. \\
r=-.64)\end{array}$ & $11-47$ & $\begin{array}{r}16(P=.15 \\
\quad r=-.34)\end{array}$ & $6-44$ \\
\hline
\end{tabular}

NOTE. Differences between control and FSHD group tested with Wilcoxon rank-sum test; $P$ values and effect sizes are shown in parentheses.

Abbreviations: EMG, electromyography; H2M, hand to the mouth; IQR, interquartile range; Max, maximum; PP, pushing/pulling; RFUC, reach up contralateral; RFUI, reach up ipsilateral.

* $P<.05$. 

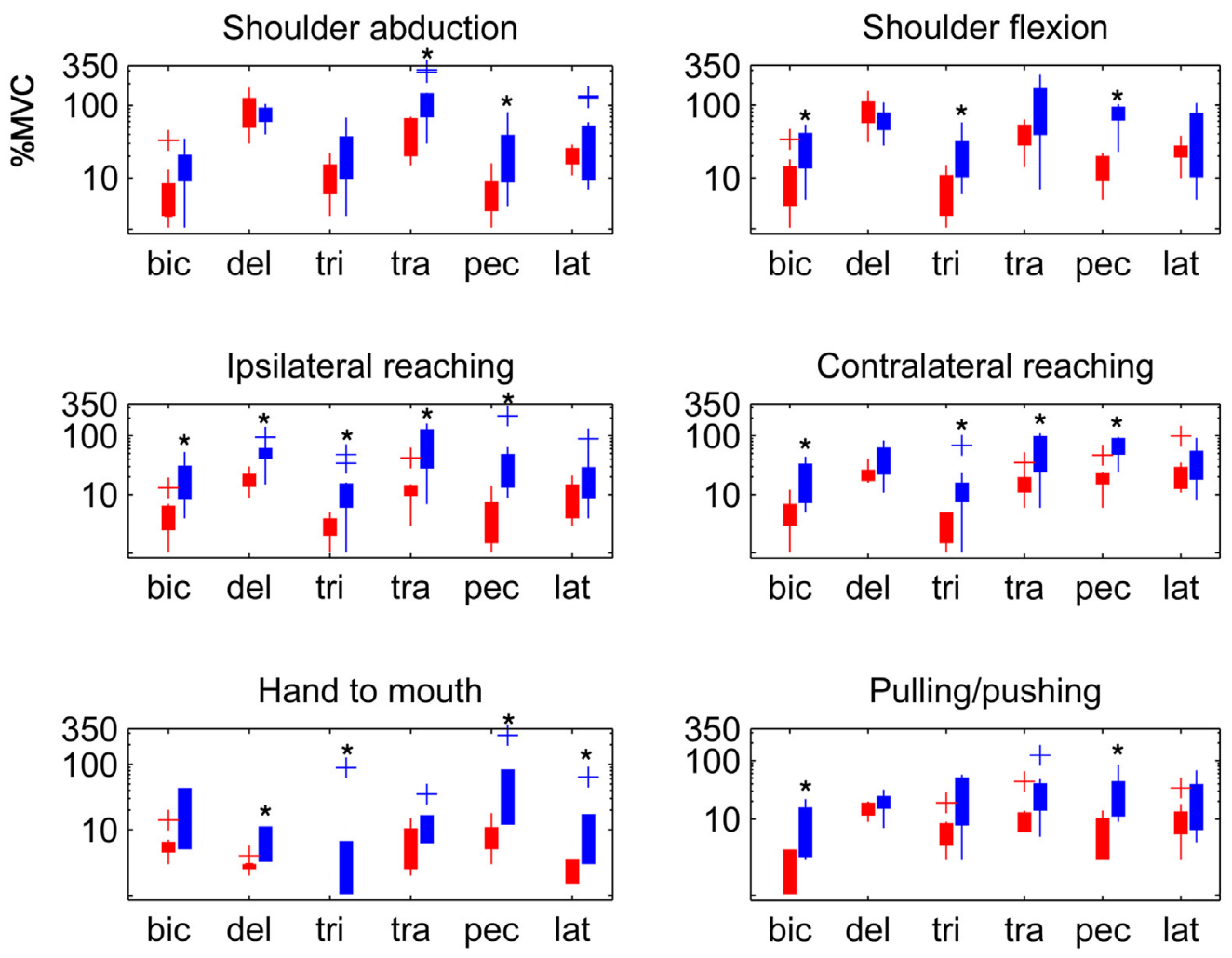

Fig 5 Boxplots of maximum muscle activation as \%MVC during performance of predefined tasks. Red bars represent interquartile ranges of the muscle activity as \%MVC on a logarithmic scale of the control group; blue bars represent interquartile ranges of the FSHD group. Plusses represent outliers, and asterisks represent comparisons that are significantly different. Abbreviations: bic, biceps brachii; del, deltoid; lat, latissimus dorsi; pec, pectoralis major; tra, trapezius; tri, triceps brachii.

influenced the performance of MVC in subjects with FSHD and consequently resulted in percentages above $100 \%$ of MVC during the execution of movements and tasks. Another explanation could be that differences exist between the electromyographic amplitude of maximal isometric contractions in MVC and the electromyographic amplitudes during maximal dynamic contractions. Bobbert et $\mathrm{al}^{34}$ have indicated that muscle activity during a maximal isometric contraction is smaller than during a maximal concentric contraction, and electromyographic amplitude increases when movement velocity increases. Moreover, force measurements were not performed in this study. Electromyographic data and 3dimensional kinematics were recorded to study the movements of the arms in FSHD, and MVC was performed to indicate relative muscle activity for each of the 6 individual muscles. The relation between electromyographic activity and force produced has been extensively investigated in healthy subjects. ${ }^{35}$ There may be consensus that the electromyography-force relationship is linear under isometric conditions and nonlinear under isotonic conditions, ${ }^{35}$ although force prediction is still approximate at best. In contrast, the relationship between electromyography and force in FSHD still has not been studied. It can be hypothesized that persons with FSHD have fewer normal working muscle fibers and that the maximum force they can produce is therefore reduced compared with healthy persons. To perform a certain activity, a minimum of force is needed that is comparable for healthy persons and persons with FSHD (eg, to lift the weight of the arm). People with FSHD need to recruit a higher percentage of available muscle fibers to achieve the required force, resulting in a higher \% MVC. Although activity percentage indicates the required muscle effort to perform the movements, it provides no information about the exact forces generated.

Activity of the serratus anterior muscle, which is an important scapula stabilizer, was not recorded in this study. The reason for this omission is the limited accessibility of the serratus anterior by surface electromyography.

Another limitation was the sample size, which consisted of 11 subjects with FSHD. However, the study was explorative, and despite the limited sample size, significant differences between movement patterns and muscle activities have been shown between healthy controls and subjects with FSHD.

To further investigate muscle capacities, a combination of external force measurements, such as dynamometry, is recommended. Together with 3-dimensional motion characteristics and electromyography, external force measurements would provide a more complete understanding, because then the role of individual muscles can also be better estimated. The used method with surface electromyography is not applicable for muscles that are not superficial, such as the rotator cuff muscles. The current investigation of 6 muscles provided an initial understanding of the activities of the superficial shoulder muscles. However, the study was not focused on kinematic analysis of scapular movements and therefore does not provide a complete representation of the scapulohumeral motions. Investigating the involvement of rotator cuff muscles and deeper muscles such as the serratus anterior would require more invasive techniques such as fluoroscopy or intramuscular needle electromyography. As part of a complementary approach to understanding rotator cuff muscle contributions, biomechanical musculoskeletal models ${ }^{21,36,37}$ could also be used. 
As a long-term research perspective, it would be interesting to further evaluate whether the use of arm supports would result in more efficient movements that require less effort and would therefore enable the performance of tasks such as eating for longer periods. It could be hypothesized that arm supports would reduce the effort to perform movements during daily activities. In this study, the FSHD data were heterogeneous, implying that a 1-sizefits-all approach may not be adequate but that a personalized approach would be needed to customize future arm supports. Understanding the effect of FSHD on muscle force and arm movements could help develop more biomechanically oriented assistive arm devices. Ideally, an arm support would counteract gravity, thus allowing the users freedom to move their arm with limited effort. There are 2 different issues: (1) the problem of scapula control and the role of the serratus anterior; and (2) the problem of UE weakness leading to muscle fatigue and impairments in performing daily tasks. For both problems, an arm support would be helpful to enable persons with FSHD to perform daily tasks better. By counteracting gravity, less force is needed to lift the arm and thus less activation of the muscles, resulting in less fatigue. Further research is required to determine what the effect of arm support is on scapula control and fatigability.

\section{Conclusions}

This is the first study where the involvement of proximal, superficial scapulohumeral muscles during several standardized movement tasks in FSHD was explored and described. Compensations were found in subjects with FSHD as a consequence of loss of muscle function; this resulted in increased muscle cocontraction and ultimately an increased effort and energy needed to accomplish tasks. The trapezius muscle was highly active in the shoulder abduction and flexion movements, indicating a mechanism that compensates for the lack of scapular lateral rotation when the arm is elevated. Persons with FSHD used higher percentages of MVC in the weakened shoulder muscles during movements and tasks that required elevation in the shoulder joint. Further research should focus on investigating whether existing arm support systems reduce these muscular efforts, so that movements or tasks can be performed longer or more frequently.

\section{Suppliers}

a. Vicon Motion Systems Ltd, 14 Minns Business Park, West Way, Oxford OX2 OJB, UK.

b. Delsys Inc, 650 Beacon St, Boston, MA 02215.

\section{Keywords}

Activities of daily living; Biomechanical phenomena Electromyography; Facio-scapulo-humeral dystrophy; Muscular dystrophies; Rehabilitation; Upper extremity

\section{Corresponding author}

Arjen Bergsma, MSc, Donders Centre for Neuroscience, Department of Rehabilitation/Occupational Therapy 898, Radboud University Medical Center, PO Box 9101, 6500 HB, Nijmegen, The Netherlands. E-mail address: arjen.bergsma@radboudumc.nl.

\section{References}

1. Emery AEH. The muscular dystrophies. Lancet 2002;359:687-95.

2. Padberg GW, Frants RR, Brouwer OF, Wijmenga C, Bakker E, Sandkuijl LA. Facioscapulohumeral muscular dystrophy in the Dutch population. Muscle Nerve Suppl 1995;2:S81-4.

3. Emery AE. Population frequencies of inherited neuromuscular diseases - a world survey. Neuromuscul Disord 1991;1:19-29.

4. Pandya S, King WM, Tawil R. Facioscapulohumeral dystrophy. Phys Ther 2008;88:105-13.

5. Tawil R, Van der Maarel SM. Facioscapulohumeral muscular dystrophy. Muscle Nerve 2006;34:1-15.

6. Kilmer DD, Abresch RT, McCrory MA, et al. Facioscapulohumeral muscular dystrophy. Am J Phys Med Rehabil 1995;74(5 Suppl):S131-9.

7. Royden JH, De Vivo DC, Darras BT. Neuromuscular disorders of infancy, childhood, and adolescence: a clinician's approach. Philadelphia: Butterworth-Heinemann; 2003.

8. Voight ML, Thomson BC. The role of the scapula in the rehabilitation of shoulder injuries. J Athl Train 2000;35:364-72.

9. Reinold MM, Escamilla RF, Wilk KE. Current concepts in the scientific and clinical rationale behind exercises for glenohumeral and scapulothoracic musculature. J Orthop Sports Phys Ther 2009;39:105-17.

10. Brouwer OF, Padberg GW, Van der Ploeg RJO, Ruys CJM, Brand R. The influence of handedness on the distribution of muscular weakness of the arms in facioscapulohumeral muscular dystrophy. Brain 1992; 115:1587-98.

11. Personius KE, Pandya S, King WM, Tawil R, McDermott MP. Facioscapulohumeral dystrophy natural history study: standardization of testing procedures and reliability of measurements. Phys Ther 1994;74:253-63.

12. FSH-DY Group. A prospective, quantitative study of the natural history of facioscapulohumeral muscular dystrophy (FSHD): implications for therapeutic trials. The FSH-DY Group. Neurology 1997;48:38-46.

13. Stubgen J-P, Stipp A. Facioscapulohumeral muscular dystrophy: a prospective study of weakness and functional impairment. J Neurol 2010;257:1457-64.

14. Bakhtiary AH, Phoenix J, Edwards RHT, Frostick SP. The effect of motor learning in facioscapulohumeral muscular dystrophy patients. Eur J Appl Physiol 2000;83:551-8.

15. Hughes AM, Freeman CT, Burridge JH, et al. Shoulder and elbow muscle activity during fully supported trajectory tracking in neurologically intact older people. J Electromyogr Kinesiol 2009;19:1025-34.

16. Prange GB, Kallenberg LAC, Jannink MJA, et al. Influence of gravity compensation on muscle activity during reach and retrieval in healthy elderly. J Electromyogr Kinesiol 2009;19:e40-9.

17. Hughes AM, Freeman CT, Burridge JH, Chappell PH, Lewin PL, Rogers E. Shoulder and elbow muscle activity during fully supported trajectory tracking in people who have had a stroke. J Electromyogr Kinesiol 2010;20:465-76.

18. Prange GB, Krabben T, Renzenbrink GJ, Ijzerman MJ, Hermens HJ, Jannink MJ. Changes in muscle activation after reach training with gravity compensation in chronic stroke patients. Int J Rehabil Res 2012;35:234-42.

19. Brooke MH, Fenichel GM, Griggs RC, et al. Clinical investigation in Duchenne dystrophy: 2. Determination of the power of therapeutic trials based on the natural history. Muscle Nerve 1983;6:91-103.

20. Vicon Motion Systems Ltd. Upper limb model product guide revision 1.0. Oxford: Vicon Motion Systems; 2007.

21. van der Helm FCT. Analysis of the kinematic and dynamic behavior of the shoulder mechanism. J Biomech 1994;27:527-50.

22. Hermens HJ, Freriks B, Merletti R, et al. European recommendations for surface electromyography. Enschede: Roessingh Research and Development; 1999.

23. Delagi EF, Iazzetti J, Perotto AO, Morrison D. Anatomical guide for the electromyographer. 5th ed. Springfield: Charles C. Thomas; 2011.

24. Wu G, van der Helm FC, Veeger HE, et al. ISB recommendation on definitions of joint coordinate systems of various joints for the reporting of human joint motion-part II: shoulder, elbow, wrist and hand. J Biomech 2005;38:981-92. 
25. Wattanaprakornkul D, Halaki M, Boettcher C, Cathers I, Ginn KA. A comprehensive analysis of muscle recruitment patterns during shoulder flexion: an electromyographic study. Clin Anat 2011;24:619-26.

26. Copeland SA, Levy O, Warner GC, Dodenhoff RM. The shoulder in patients with muscular dystrophy. Clin Orthop Relat Res 1999;368: 80-91.

27. Reed D, Cathers I, Halaki M, Ginn K. Does supraspinatus initiate shoulder abduction? J Electromyogr Kinesiol 2013;23:425-9.

28. Martin RM, Fish DE. Scapular winging: anatomical review, diagnosis, and treatments. Curr Rev Musculoskelet Med 2008;1:1-11.

29. Warner JJ, Micheli LJ, Arslanian LE, Kennedy J, Kennedy R. Scapulothoracic motion in normal shoulders and shoulders with glenohumeral instability and impingement syndrome A study using Moire topographic analysis. Clin Orthop Relat Res 1992;285:191-9.

30. Demirhan M, Uysal O, Atalar AC, Kilicoglu O, Serdaroglu P. Scapulothoracic arthrodesis in facioscapulohumeral dystrophy with multifilament cable. Clin Orthop Relat Res 2009;467:2090-7.

31. Itoi E, Kuechle DK, Newman SR, Morrey BF, An KN. Stabilising function of the biceps in stable and unstable shoulders. J Bone Joint Surg Br 1993;75:546-50.
32. Schillings ML, Kalkman JS, Janssen HMH, van Engelen BGM, Bleijenberg G, Zwarts MJ. Experienced and physiological fatigue in neuromuscular disorders. Clin Neurophysiol 2007;118:292-300.

33. Criswell E. Cram's introduction to surface electromyography. 2nd ed. Sudbury: Jones and Bartlett Publishers; 2011.

34. Bobbert MF, Harlaar J. Evaluation of moment-angle curves in isokinetic knee extension. Med Sci Sports Exerc 1993;25:251-9.

35. Weir JP, Wagner LL, Housh TJ. Linearity and reliability of the IEMG $\mathrm{v}$ torque relationship for the forearm flexors and leg extensors. Am J Phys Med Rehabil 1992;71:283-7.

36. Essers JMN, Murgia A, Bergsma A, Verstegen PPH, Meijer K, editors. An inverse dynamic analysis on the influence of upper limb gravity compensation during reaching. Proceedings of the International Conference on Rehabilitation Robotics; 2013 Jun 24-26; Seattle.

37. Veeger HEJ, Yu B, An KN, editors. Orientation of axes in the elbow and forearm for biomechanical modeling. In: Veeger HEJ, VanderHelm FCT, Rozing PM, editors. Proceedings of the 1st Conference of the International Shoulder Group; 1996 Aug 26-27; Delft (The Netherlands). Maastricht: Shaker Publishing. p 83-7. 